\title{
Editorial: European Journal of Case Reports in Internal Medicine
}

This editorial was first published online in European Journal of Internal Medicine on 04/08/2014, DOI: http://dx.doi.org/10.1016/j.ejim.2014.07.006

\section{$\underline{\text { John Kellett }}^{\text {a,b }}$}

${ }^{a}$ Editor-in-Chief of the European Journal of Case Reports in Internal Medicine

${ }^{b}$ Associate Editor of the European Journal of Internal Medicine

\section{Abstract:}

Modern medicine began in the last half of the nineteenth century when doctors started practising the scientific method at the bedside. However, in his presidential address to the Association of American Physicians in 1979 James Wyngaarden postulated that the clinical scientist was an endangered species [1]. Several reasons for this have been suggested, including "the seductive incomes that now derive from procedure-based specialty medicine". Others have suggested that it is simply because the things left to be discovered at bedside have become exhausted, and that all the big medical advances will now be made by high-powered institutions

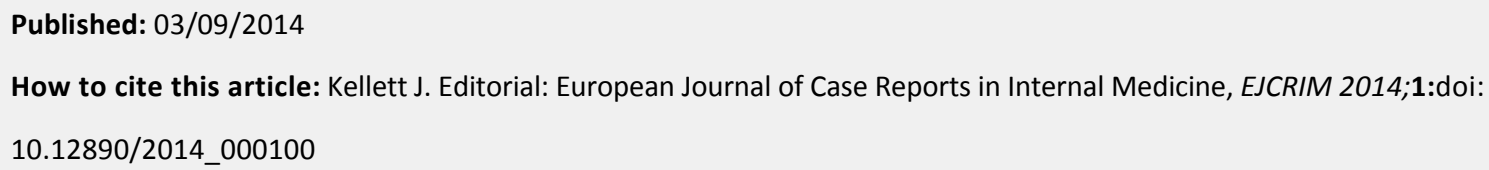


Modern medicine began in the last half of the nineteenth century when doctors started practising the scientific method at the bedside. However, in his presidential address to the Association of American Physicians in 1979 James Wyngaarden postulated that the clinical scientist was an endangered species [1]. Several reasons for this have been suggested, including "the seductive incomes that now derive from procedure-based specialty medicine". Others have suggested that it is simply because the things left to be discovered at bedside have become exhausted, and that all the big medical advances will now be made by high-powered institutions. This may not, however, be the case. Some of the major advances in medicine, such as the role of Helicobacter pylori in peptic ulcer disease, are still made by bedside clinicians. Furthermore, how are "high-powered" institutions going to do any medical research if there are no more doctors interested in research?

One very simple reason why fewer doctors are interested in clinical research is that it is difficult to get started. Nearly all of us who consider ourselves to be clinical scientists started off by publishing a case report. We saw an interesting or unusual case, researched the literature, presented it to our colleagues, wrote it up, published it and added it, as another notch, to our curriculum vitae as we tried to climb the next rung of our career's ladder. For the last twenty years or so this has become more difficult to do. Since case reports do not increase a journal's impact factor most journals are now reluctant to publish them. A few years ago EJIM became inundated with a large number of case reports of hitherto unreported and hence rare conditions. At that time the editors felt strongly that conditions not yet reported in the medical literature are likely to be so rare that they are unlikely ever to be encountered again and certainly not within the lifetime of the practising physicians who read our journal. Also many of these case reports were of conditions already well described and better discussed on the internet. As a result EJIM adopted a policy of only publishing case reports of exceptional quality and interest (2).

EJIM realised at the time that this policy made it more difficult for busy clinicians to also be medical scientists and indulge in scientific enquiry. Happily things have moved on, and the paradigm of medical publishing is rapidly changing from expensive paper publications with limited capacity, to cheap electronic publications of unlimited capacity the costs of which most authors will find affordable. In this new world it is becoming increasingly clear that open access papers on the internet are much more likely to be cited and read. European Federation of Internal Medicine has, therefore, launching an electronic open access journal called the European Journal of Case Reports in Internal Medicine.

This journal is a sister publication to European Journal of Internal Medicine and provides a forum for 
internal medicine doctors to report interesting cases, or a series or cluster of cases. All papers submitted to the journal will be peer reviewed. There is a modest submission fee (currently €38.20) and in the event that a paper is accepted for publication a further modest charge will be made (currently €88.64).

Potential authors should consider the following caveats before submitting a paper to the journal:

1. Are they reporting something likely to be of interest to most of their colleagues?

2. Have they got some photographs, x-rays, CT scans of other material that illustrates their findings?

3. Is there anything new that is not easily already available on the internet?

4. Is their report to easy to read, and have they been a brief as possible?

5. Have you read the journal's Instructions to Authors?

The journal welcomes submissions from doctors everywhere. Further details can be found on the journal's website www.ejcrim.com

\section{References}

1. Wyngaarden, J.B. The clinical investigator as an endangered species. N Engl J Med 1979; 301: 1254-1259

2. Kellett, J. Case reports - EJIM's new policy. Eur J Intern Med 2008; 19: 389 